\title{
Service-Oriented Mobile Application about Cost of Water: The Case of Loja a City of Frontier in Ecuador
}

\author{
Liliana Enciso $^{1+}$, Jessica Minga ${ }^{2}$, Lisbeth Leiva ${ }^{2}$ and Elmer Zelaya ${ }^{3}$ \\ 1,2,3 Universidad Técnica Particular de Loja, Departamento de Ciencias de la Computación y Electrónica, \\ ${ }^{1}$ Grupo IoT Network Communications on Smart Environment.
}

\begin{abstract}
This document describes the processes for the development of a mobile application that has as objective, to send alerts to the user when by the end of the month for the payment of the water service. In addition you can see information about the processes and methods for the calculation of the value of drinking water and water consumption data. This application was created under the waterfall development methodology based on phases which are: Analysis where you determine the requirements and will be formalised. Design is the schema that will operate the software, the diagrams and the way to connect it uses a client-server architecture because the application needs to obtain certain features of an API is available via the internet to generate alerts the user. Implementation is put into practice all that is created during the design. Evidence: is simulated with the implementation of the different utilities, taking into account the performance and its potential. Maintenance and Operation is placed in observation, taking into account the possible damage or arrangements. For the creation of this application was used tools such as Android Studio, SqLite database, the Android API Firebase, as a conclusion, it was clear that the applications developed in android Studio allow developers to use tools that facilitate the implementation of more practical features that make mobile applications, due to the existence of varieties of API's.
\end{abstract}

Keywords: SAP: potable water service, Meter, Drinking Water, Water Consumption, meter reading, Android, SQLite, Mobile, App.

\section{Introduction}

Water is the most important element for the life of all living beings and is one of the factors involved in the development of the various forms of life. This item comprises the $3 / 4$ parts of the planet, that is, it represents the $71 \%$ of the volume of the Earth, this percentage $961 \%$ is salt water corresponding to oceans and seas, the other $3 \%$ is located at the poles and glaciers, while the rest corresponds to fresh water belonging to water vapor, rivers and lakes[1]. The water is of great importance for the reduction of the rate of mortality. At present the coverage of water supply and sanitation in Ecuador has increased considerably in recent years, but there are still areas of the rural areas that do not have this service [2]. The Water that is now an indispensable service is obtained after improving the quality of the raw water through a series of highly industrialized processes which are the collection of raw water from the sources of fresh water then occurs the water so that it can be distributed to the people of the communities, and cities [3][4]. The "Public Company EMMAL-EP Municipal Water and Sewer System "is responsible for the distribution of drinking water in the city of Loja, for the payment of the service each client must get closer to the facilities of this unit to pay. The problem presented in this process is that when the client is about to pay still does not know the amount of your consumption of water, causing loss of time both to the person in charge of the collection of the service to the customer if this does not have enough money for the payment, or in the worst case if your presence on the premises is only to see the amount to be paid. This mobile application depends on the information obtained through the company EMMAL-EP, data that we provide for the costs of the service depending on the meter

\footnotetext{
${ }^{+}$Corresponding author. Tel.: +593-7-3701444; fax: +000-0-0000000.
}

E-mail address: lenciso@utpl.edu.ec 
readings entered by user, in addition is aimed at users that have an Android mobile device [5], and who believe essential to have an alert to pay for their service. The tools used in the implementation proposal are: ANDROID STUDIO, in addition to the powerful code editor and tools for developers of IntelliJ, Android Studio offers even more features that increase your productivity during the compilation of apps for Android [6][7].

\section{Related Works}

At present you can observe several similar products, An example is Light Price mobile application available in Play Store that allows consultation of the prices of electrical services in Spain [8]. The capital azuaya consolidated in a mobile application developed for IOS and Android platforms that allows consultation of the services of electricity, water, telephone, among others, this can be downloaded from Apple Store and Play Store[9]. A similar application is a reminder of bill payment free app that sends notices of the bills on time and makes it possible to manage your monthly budget review next monthly expenses [10]. The authors realize a calculation of the annual consumption in function of the direct consumption of water, food consumption and the consumption of industrial products [11][12]. As well as the BBC online tool that takes into account the consumption of water in the bathroom, kitchen and exterior (garden and car wash) [13], another is the tool that allows you to make esval a quick calculation of water consumption in your home by entering the time and number of times used the artifacts that need water, this is a tool developed for the community of Chile [14]. In the table 1., we can observe a comparation of the different jobs related. Have also been identified web portals that allow users to know the average water consumption per household, as well as some of these give to know the electrical consumption and even the value of unpaid bills, unlike these projects, the called Smart Cost of Water calculating the value to pay for each month of the drinking water service in the city of Loja through of the mobile application.

Table 1: Comparative analysis of the Work Related

\begin{tabular}{|l|c|l|l|}
\hline Name & Type & \multicolumn{1}{|c|}{ Available at } & \multicolumn{1}{c|}{ Service } \\
\hline Ligth Price & Free App & Play Store & Electric Ligth of Spain \\
\hline $\begin{array}{l}\text { Mobile } \\
\text { Consultations Basin }\end{array}$ & Free & Apple App Store and Play Store & Electric Power, water, telephone and more \\
\hline $\begin{array}{l}\text { Bill Payment } \\
\text { Reminder }\end{array}$ & Free App & Play Store & $\begin{array}{l}\text { Payment of monthly invoices entered by } \\
\text { the user }\end{array}$ \\
\hline Water Foot Print & Web portal & http://waterfootprint.org/en/ & Drinking Water \\
\hline BBC & Web portal & $\begin{array}{l}\text { http://www.bbc.co.uk/spanish/flash/swf/w } \\
\text { ater_calculator/water_calculator2.swf }\end{array}$ & Drinking Water \\
\hline Esval & Web portal & http://www.esval.cl/calcula.html & Agua Potable \\
\hline
\end{tabular}

\section{Theoretical Framework}

\subsection{Smartphone and Mobile Applications}

The smartphone is device created with mobile operating systems that have a large data capacity, connectivity and installation of programs known as mobile applications. In the 2015, 3'084,886 Ecuadorian reported having a smartphone, almost five times higher than that reported in the 2011 when the figure was 522,640 people [15]. Mobile applications are those that were developed to run on mobile devices [16]. To develop software of this type has to take into account certain restrictions that have the hardware of these devices, such as, for example, that are small, have low computing power, storage capacity, limited bandwidth, etc [17][18][19]. A mobile operating system is the one who controls a mobile device, similar to computers using Windows or Linux and other OS. However, the mobile operating systems are much simpler and are more geared to the wireless connectivity [20][21]. One of the platforms currently used for mobile applications is Android, with $28 \%$ of developers on this platform [22].

\subsection{Types of Mobile Applications}

One of the main choices that have an application developer is to choose a type of application generally divided into three types [22][23]: Native applications.- are those developed to run on an operating system with specific platforms and which are developed in the native language of each device. For example, to 
develop Java is used on Android, iOS in Objective C, and now also the new Swift, and on Windows Phone is used C\\# and Visual Basic.NET [24]. Web applications. - Refers to a web site optimized for mobile devices its principal attribute is that it can be viewed on any device. They are also called WebApp developed in HTML, JavaScript and CSS [25]. Hybrid applications. - written in HTML5, CSS3 and Javascript to be executed in a browser, this code is compiled into an executable file and creates a cross-platform application that can be distributed through the app stores [26].

\subsection{Methodology Waterfall and Firebase Cloud Messaging (FCM)}

The programming methodology in cascade is also called Life Cycle Classic, was proposed by Winston W. Royce (1929 - 1995) at the beginning of the years 70, and it is basically made up of [27]:

- Analysis of the requirements.- is to process as an analyst is a study on the requirements collected in advance and review of documents.

- Software Design.- a study of the main points of the design of the system, the same that are based on inputs outputs and processing of the same.

- Implementation.-translates the design in machine - readable code.

- Unit tests.-measured the results of the product encoded and approved by the client is assured.

- Maintenance and Operation.-surrender executable design manuals and user.

It is a cross-platform solution that allows you send, free of charge and secure, messages and notifications. When using WCF, you can notify a client app that a new email or other data are available for synchronization. You can send notifications for receiving stolen goods and increase user retention. For use cases such as instant messaging, a message you can transfer a load of up to $4 \mathrm{~KB}$ to a PPP client [28] [29]. This service is offered by Google in a simple way for their integration, and use.

\subsection{Cost of water in Loja}

In Loja according to the Head of Marketing of UMAPAL: there are 41984 contributors in the RESIDENTIAL category; in the commercial category, i.e. businesses, homes and other "renteras" are recorded a total of 5040 farms; while in the public sector there are 186 users [30]. In the event of a leak or excessive expenditures of the water will have an impact on the cost of water that will be reflected in the cost of your service. The values in the table 2 in addition to be obtained from the service consumed value of drinking water are added to the same, others, forming the total payment.

Table 2: Tariff of water

\begin{tabular}{|l|c|c|c|c|c|c|}
\hline & \multicolumn{2}{|c|}{ Residential } & \multicolumn{2}{c|}{ Commercial } & \multicolumn{2}{c|}{ Industrial } \\
\hline Range & Base & Increase \$/m3 & Base & Increase \$/m3 & Base & Increase \$/m3 \\
\hline $0-10$ & 2.025 & ------------ & 8.675 & ------------ & 12.685 & \\
\hline $11-20$ & 3.113 & 0.120 & ------- & 0.438 & ------- & 0.651 \\
\hline $21-50$ & 4.460 & 0.222 & ------- & 0.692 & ------- & 1.046 \\
\hline $51-70$ & 14.003 & 0.273 & ------- & 0.862 & ------- & 1.300 \\
\hline $71-90$ & 24.462 & 0.317 & ------- & 0.862 & ------ & 1.300 \\
\hline $91-100$ & 31.702 & 0.438 & ------ & 0.862 & ------ & 1.300 \\
\hline 101 y mas & 38.613 & 0.521 & ------ & 1.300 & ------ & 1.955 \\
\hline
\end{tabular}

\section{Methodology}

This application is intended to make the users know the value of the consumption of its potable water service (SAP), by entering the number that your meter in $\mathrm{m} 3$ This will allow the user to an estimated amount of value to pay, without the need for it to be mobilized to the facilities of the company providing the service, in addition to the application will send alerts of the estimated dates in which your new monthly value to pay.

In the figure 1, shows the architecture of the application to develop. This system consists with the intervention of a user, which you can get access to this by means of a mobile application that can be installed on devices with Android operating system. Through this application, the user can log on and in the first in- 
stance, you must enter the required values for the calculation, and thus obtain the estimated value to pay in the month.

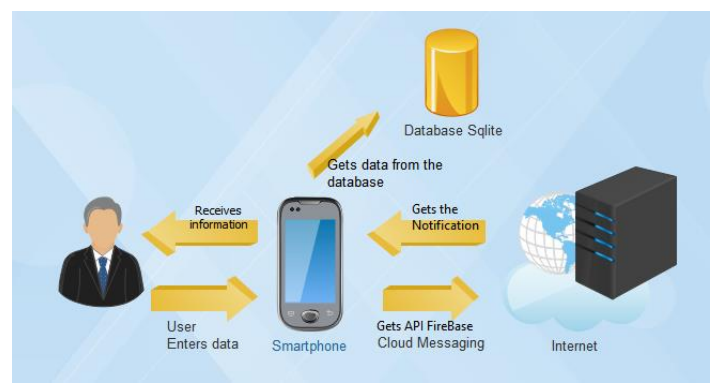

Fig. 1: Architecture of the application developed.

The methodology used for the completion of this project is based in phases, based on the cascade development model, so that the start of each one must wait for the completion of the previous one.

1. Analysis of the requirements: in this phase are analyzed the needs of the end users of the application to determine which services, constraints and objectives must be covered.

\section{Functional Requirements}

(a) The application will allow to enter the last payment you have and the current number of meter.

(b) The application shall have system for calculating how much it costs to the value of the invoice to pay for water billing.

(c) The application shall provide alerts on the day in which you are going to leave the water billing invoice.

(d) Once in the application shall be paid each time it is required to use the previous value and the current.

(e) You can list all the previous values.

\section{Non-functional requirements}

(a) For the operation of the application must be connected to the Internet.

(b) The application must be reliable, efficient and quality.

(c) Hold the operating system Android 3.0 on-wards.

(d) Will be unique to each Android device.

2. Software design: In this phase, is established both the architecture that will have the application, the database to store user data and finally the interface:

(a) Database: The database engine Sqlite manager transactional database for mobile operating systems [20], Allows us to create related tables in the database model, such as the presentation of a primary table in this case called User and other tables that are Data y Meter, the same that are linked to this via the id which would be the primary key of the table User and foreign key of the other.

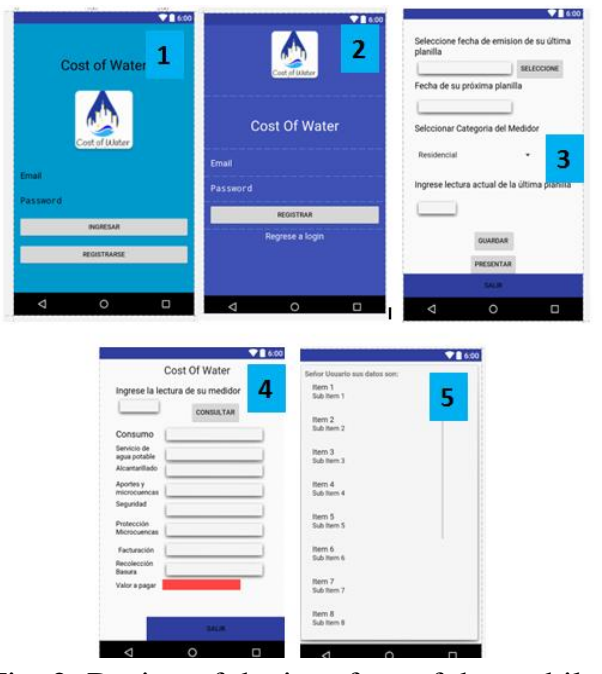

Fig. 2: Design of the interface of the mobile application.

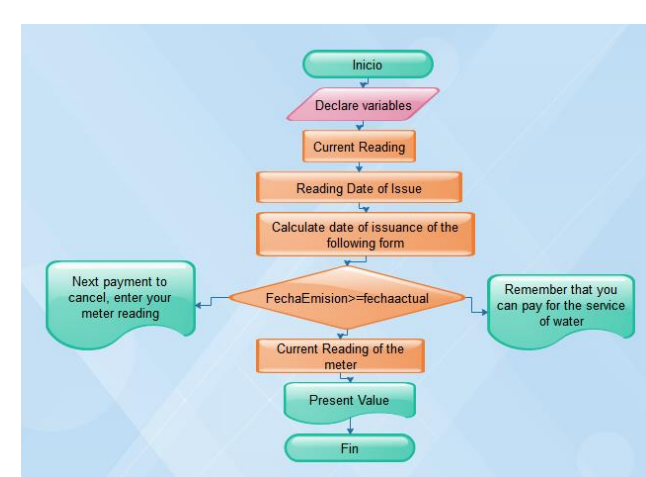

Fig. 3: The process diagram of the application. 
(b) Design of the Interface: To perform the application it was thought appropriate, create a login for each user according to their id. In the figure 2, shows are screens:(1) the login to enter into the application, (2) the interface of registry, (3) the window where the values of the form, (4) the values present in case of calculation and (5) present the user data stored. In the figure 3, shows the process diagram of the application.

3. Implementation: In this phase is the construction of modules and units of software that developed in the IDE Android Studio below you will see the most important methods and a brief explanation of the same:( Listing. 1)

Creation of tables: Code where tables are created, in this case the table of users with the corresponding SQL statement.

Listing 1: Method for Create Table

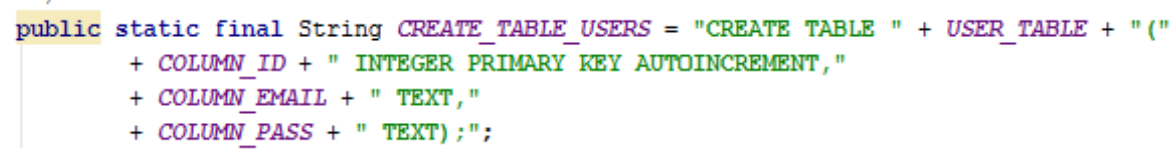

Data in the Database SQlite: In this method adds information in the data table, you need to use the class SQliteDatabase(allows you to run any SQL statement on the basis of data) and the method of the same .query(for consultations).( Listing. 2)

Listing 2: Method for sending values to the tables

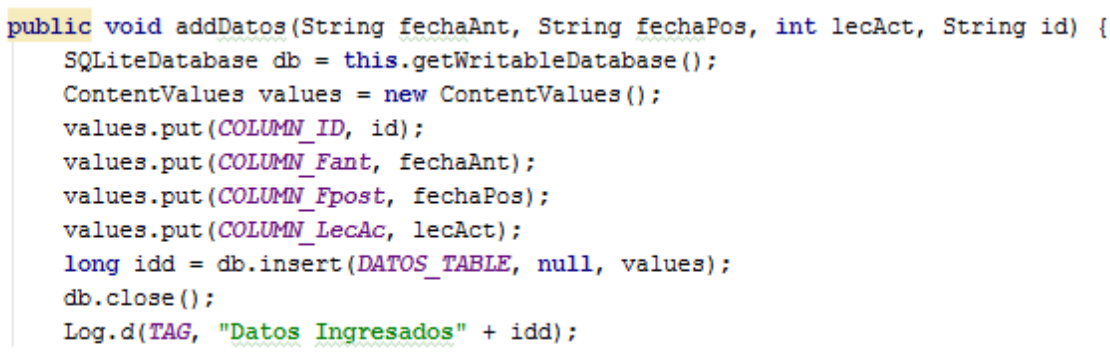

Notifications: By means of this method is presented push notifications that are sent from Fire-base to application, and use the Notification- Manager class (responsible for managing notifications that are to be displayed in the Notifications bar), Intent (serves to invoke components), and Pending Intent(object is the one that allows external components that run a section of code below).( Listing. 3)

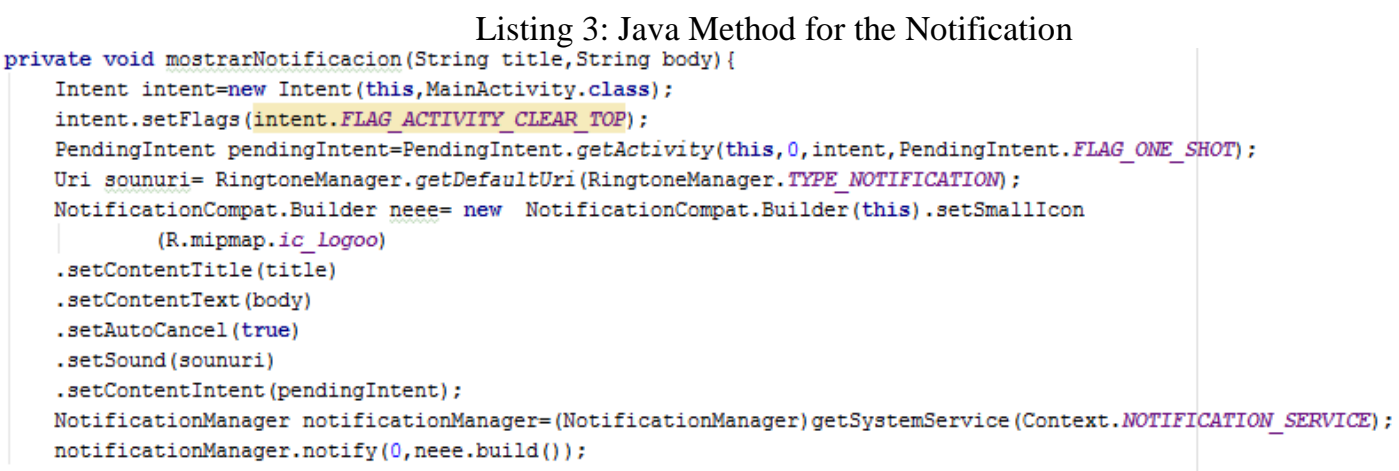

1. System tests and integration: The evidence of the application will begin to perform, obtaining favorable results where it helps users.

2. Maintenance and Operation: The system is put in place and the correction of errors discovered and corrected at a later date, taking into account that this application can get to cover new needs in the future, but for the moment covers the proposed requirements.

\section{Results}

The implementation Cost Of Water presents in its interface a panel for the user registration and logging, data that is recorded in a database, available panel in the figure 4. Once the user enters the application the date of issuance of the last invoice paid, which will generate the date of issuance of the future form to pay, you must also select the type of meter that has and enter the current reading of the last payroll paid. When the 
estimated date for the departure of the next return the user will receive a notification device, where you will be prompted to enter the meter reading, which is an important step so that you can see the value to pay by drinking water service.
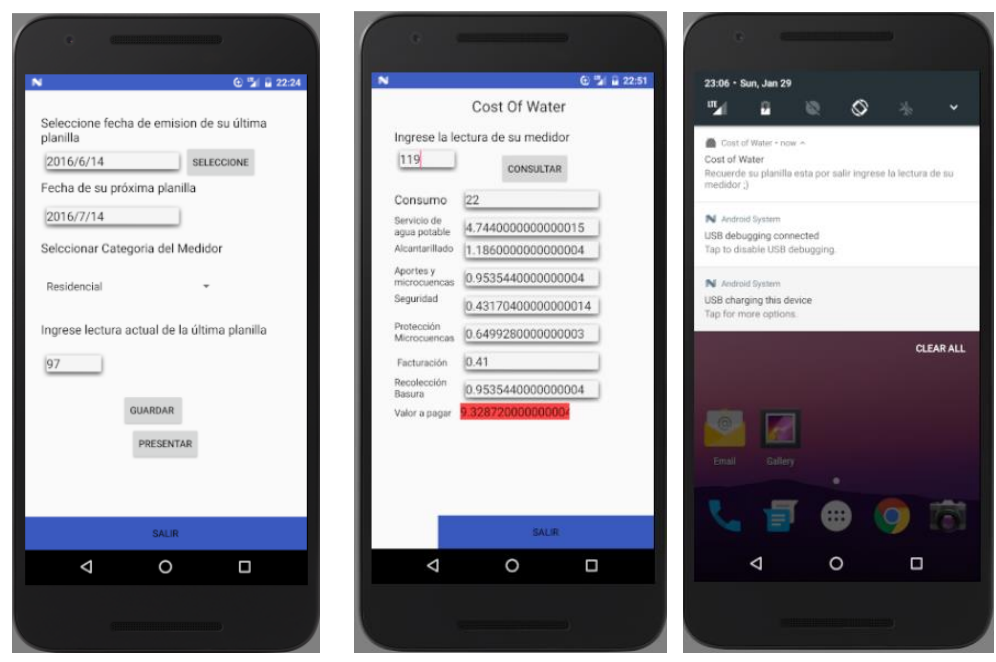

Fig. 4: Results of the Application.

Taking into account the principle of users on the implementation, positive results were obtained as:

- Novel application for the user

- Long-term usefulness

- Send reminders of the period in which you must pay for your return.

- Creation of a functional system, which achieves the intended goal of service to the user.

On the other hand within the negative this application, is only defined for Android, the features still need to continue to develop and because it does not have a direct link with UMAPAL values will not be accurate is to say, they will have little room for error due to the fact that the bases and increases change, although at the moment have been adequate for the needs of the users. This application of the future can get to have new features that will help more and contribute, either by sending alerts on water consumption in certain hours or any alteration that can be caused by a fault, you can also take into account that can in- crease its functionality to obtain not only the cost of the service for water, but rather for other services such as light or even to review fines of the Municipality of Loja.

\section{Conclusion}

Applications created within Android Studio, whose native language is Java are easy to handle, due to the fact that Android has tools that provide various services such as the use of the Api Google Messaging Firebase Cloud that can send push notifications process for which it is necessary that the cell phone is connected to the Internet through wireless network.

The creation of a mobile application by means of cascade methodology allows you to perform a job in a short time and clearly on the other hand the client/server architecture gives greater security for the data to be stored into the database. The sqlite database is effective, portable, and free use which makes it easy to carry in each application.

\section{References}

[1] Verdugo, V. and Sing, B.F.T. C. (2008). Un registro observacional del consumo individual de agua: aplicaciones a la investigación de la conducta sustentable. Revista Mexicana de Análisis de la Conducta. 200834(1):79- 96.

[2] Spellman, F. R., Drinan, J., and Berga Celma, A. (2004). Manual del agua potable. Zaragoza : Editorial Acribia, 2004.

[3] Mendez Monzons, L. (2015). La Calidad de Vida Urbana medida a travs del tipo de acceso al agua potable. el caso de Cochabamba, Bolivia. PhD thesis, Universitat Jaume I. 
[4] Esval. Agua Potable. 2016.

[5] Enciso, L., Quezada, P., Barba-Guamán, L., Solano, L., and Alarcón, P.-P. (2016). Open Drugstores Mobile App, pages 797-806. Springer International Publishing, Cham.

[6] Mocholí, A. (2016). Aprender a programar Android por donde empiezo?.

[7] Android Studio. Conoce Android Studio. 2016.

[8] Latorre,Adrian (2014). 6 Aplicaciones para saber el precio de la luz - El Androide Libre.

[9] Astudillo, G. (2015). Cuenca presentó una aplicación móvil — El Comercio.

[10] Google play (2016). Recordatorio de pago facturas - Aplicaciones Android en Google Play.

[11] Castañeda, Jorge (2016). 7 herramientas on line para calcular tu consumo de agua.

[12] Arjen Y. Hoekstra, Ashok K. Chapagain and Mesfin M. Mekonnen. (2005). Personal calculator - extended. Personal calculator - extended. http://waterfootprint.org/en/resources/interactive-tools/personal-water-footprintcalculator/personal-calculator-extended/

[13] BBC. Water calculator. 2016.

[14] Esval. (2016). Calcula tu consumo de agua potable - Esval, Comprometidos con la sequía de la región. http://www.esval.cl/calcula.html

[15] INEC. Ecuador en Cifras. Instituto Nacional de Estadística y Censos. 2016. http://www.ecuadorencifras.gob.ec/institucional/home/

[16] Blas, S. S. (2012). Aplicaciones publicitarias para móvil: conocimiento, actitudes, motivos de uso y valoración por parte de los adolescentes españoles/mobile advertising applications: Spanish teenagers' knowledge, attitudes and motives of use. Pensar la Publicidad, 6(1):255-270. Universidad Complutense de Madrid 2012.

[17] Liliana Enciso Quispe, Luis Mengual Galan, Behavior of Ad Hoc routing protocols, analyzed for emergency and rescue scenarios, on a real urban area, Expert Systems with Applications, Volume 41, Issue 5, April 2014, Pages 2565-2573.

[18] Enciso, L., Quezada, P., Fernandez, J., Figueroa, B., Espinoza, V. Analysis of performance of the routing protocols ad hoc using random waypoint mobility model applied to an urban environment (2016) WEBIST 2016 Proceedings of the 12th International Conference on Web Information Systems and Technologies, 1, pp. 208-213.

[19] Quispe, L.E., Galan, L.M. Analysis of QoS parameter in AODV a DSR in mobile Ad Hoc networks (2012) WEBIST 2012 - Proceedings of the 8th International Conference on Web Information Systems and Technologies, pp. 276-279.

[20] Vanegas, C. and Andrés, J. (2015). Aplicación móvil para transacciones, consultas e ingreso de información financiera en el sistema financial business system de la empresa sifizsoft sa. B.S. thesis, Universidad Técnica de Ambato. Facultad de Ingeniería en Sistemas, Electrónica e Industrial. Carrera de Ingeniería en Sistemas Computacionales e Informáticos.

[21] Navincopa, D., Moreno, M., Crispn, R., Small, E., and Robles-Flores, J. (2016). Desempeño de las aplicaciones móviles en las empresas. AIS Electronic Library.

[22] App, N. A., Profits, A., and Forecasts, A. E. (2015). About Vision Mobile Also by Vision Mobile Terms of re-use, (August).

[23] Zanini, V and Hereter, L. (2016). JQuery Mobile: Desarrollo de aplicaciones y portales web para dispositivos móviles .

[24] QODE(2014). Qué es una App Nativa-Blog de Tecnología Qode Apps.

[25] LanceTalent (2014). Los 3 tipos de aplicaciones móviles: ventajas e incovenientes.

[26] Financiero, E. (2012). Aplicaciones híbridas todo terreno. Copyright - Copyright (c) 2012 El Financiero.

[27] Royce, W., Managing the development of large software systems: concepts and technique, IEEE Westcon, 1970.

[28] Firebase (2016). Firebase Cloud Messaging.

[29] Lardinois, F. (2016). Google turns firebase into its unified platform for mobile developers. AOL Inc. May 18, 2016.

[30] Alvarado, R. (2016). No existe incremento en servicio de agua potable - Municipio de Loja. 